LETTER

\title{
Water at high temperatures in a microcrystalline silica (chalcedony) by in-situ infrared spectroscopy: physicochemical states and dehydration behavior
}

\author{
Junichi FUKUDA and Satoru NAKASHIMA \\ Department of Earth and Space Science, Graduate School of Science, Osaka University \\ 1-1 Machikaneyama, Toyonaka, Osaka 560-0043, Japan
}

\begin{abstract}
In order to study physicochemical states of water in a chalcedony, thin sections were heated from room temperature (RT) to $400{ }^{\circ} \mathrm{C}$ at $50{ }^{\circ} \mathrm{C}$ intervals under an infrared (IR) microscope. A sharp IR absorption band due to hydroxyls $(\mathrm{Si}-\mathrm{OH})$ shifts linearly from $3585 \mathrm{~cm}^{-1}$ at RT to $3599 \mathrm{~cm}^{-1}$ at $400{ }^{\circ} \mathrm{C}\left(1.8 \mathrm{~cm}^{-1} / 50{ }^{\circ} \mathrm{C}\right)$. A broad band due to $\mathrm{H}_{2} \mathrm{O}$ shifts also linearly from $3425 \mathrm{~cm}^{-1}$ at RT to $3535 \mathrm{~cm}^{-1}$ at $400{ }^{\circ} \mathrm{C}\left(15 \mathrm{~cm}^{-1} / 50{ }^{\circ} \mathrm{C}\right)$. These reversible band shifts, without dehydration, of hydroxyl and $\mathrm{H}_{2} \mathrm{O}$ can be explained by the increasing hydrogen bond distance and the decreasing coordinating numbers of water molecules, respectively.

The in-situ IR spectra of the chalcedony thin sections during the isothermal heating at $550{ }^{\circ} \mathrm{C}$ showed a decrease of the total water band area. The RT spectra quenched from $550{ }^{\circ} \mathrm{C}$ indicated the major decrease of $3585 \mathrm{~cm}^{-1}$ absorbance due to $\mathrm{Si}-\mathrm{OH}$ with the minor decrease of the $3425 \mathrm{~cm}^{-1}$ absorbance due to $\mathrm{H}_{2} \mathrm{O}$. These results suggest the dominant dehydration of $\mathrm{Si}-\mathrm{OH}$ species from the microcrystalline quartz and the certain stability of liquid-like $\mathrm{H}_{2} \mathrm{O}$ against dehydration in pores and grain boundaries.
\end{abstract}

Keywords: Hydroxyl, $\mathrm{H}_{2} \mathrm{O}$, Dehydration, In-situ IR spectroscopy, Hydrogen bond

\section{INTRODUCTION}

In the earth's surface materials, water exists as hydroxyls in crystal structures and as $\mathrm{H}_{2} \mathrm{O}$ in pores and grain boundaries between minerals (e.g., Farver and Yund, 1992; Hiraga et al., 2001; Ito and Nakashima, 2002). One of simple materials including these hydroxyls and $\mathrm{H}_{2} \mathrm{O}$ is chalcedonic quartz. Chalcedony is mostly composed of microcrystalline quartz (Flörke et al., 1991). Water in chalcedony was studied by infrared (IR) spectroscopy to be present as hydroxyls $(\mathrm{Si}-\mathrm{OH})$ mainly in crystal defects and as liquid water $\left(\mathrm{H}_{2} \mathrm{O}\right)$ (e.g., Frondel, 1982; Graetsch et al., 1985). In-situ high temperature IR spectroscopy has been conducted for studying different states of water in quartz and chalcedony (Yamagishi et al., 1997; Suzuki and Nakashima, 1999). Suzuki and Nakashima (1999) reported high temperature IR spectra of hydroxyl associated with $\mathrm{Al}^{3+}$ defect in quartz single crystal and showed the remarkable $\mathrm{OH}$ frequency change upon $\alpha \rightarrow \beta$ quartz transitions. Yamagishi et al. (1997) showed IR spectral

doi:10.2465/jmps.071022a

J. Fukuda, jfukuda@ess.sci.osaka-u.ac.jp Corresponding author

S. Nakashima, satoru@ess.sci.osaka-u.ac.jp changes with temperature for water in chalcedony. However, these authors did not discuss quantitatively changes with temperature of physicochemical states and dehydration behavior of water.

In this study, we first conducted in-situ step heating IR experiments of a chalcedony to evaluate frequency changes of hydroxyl and $\mathrm{H}_{2} \mathrm{O}$ absorption bands at high temperatures. Then, in-situ isothermal IR spectra and their room temperature (RT) spectra quenched from high temperature have been studied. Dehydration behavior of hydroxyl and $\mathrm{H}_{2} \mathrm{O}$ from the microcrystalline quartz will be reported.

\section{MATERIALS AND EXPERIMENTAL MEHODS}

Doubly polished thin sections were prepared from a microcrystalline chalcedony block from Chayagawa, Oshamanbe, South-West Hokkaido, Japan (the same block as Yamagishi et al., 1997). Under a polarizing microscope, the sample thin section shows the negative elongation (length-fast) and rhythmic extinctions (Runzelbänderung) (Graetsch, 1994). From powder X-ray diffraction, the size of crystallite was estimated to be $300 \AA$ and weak 


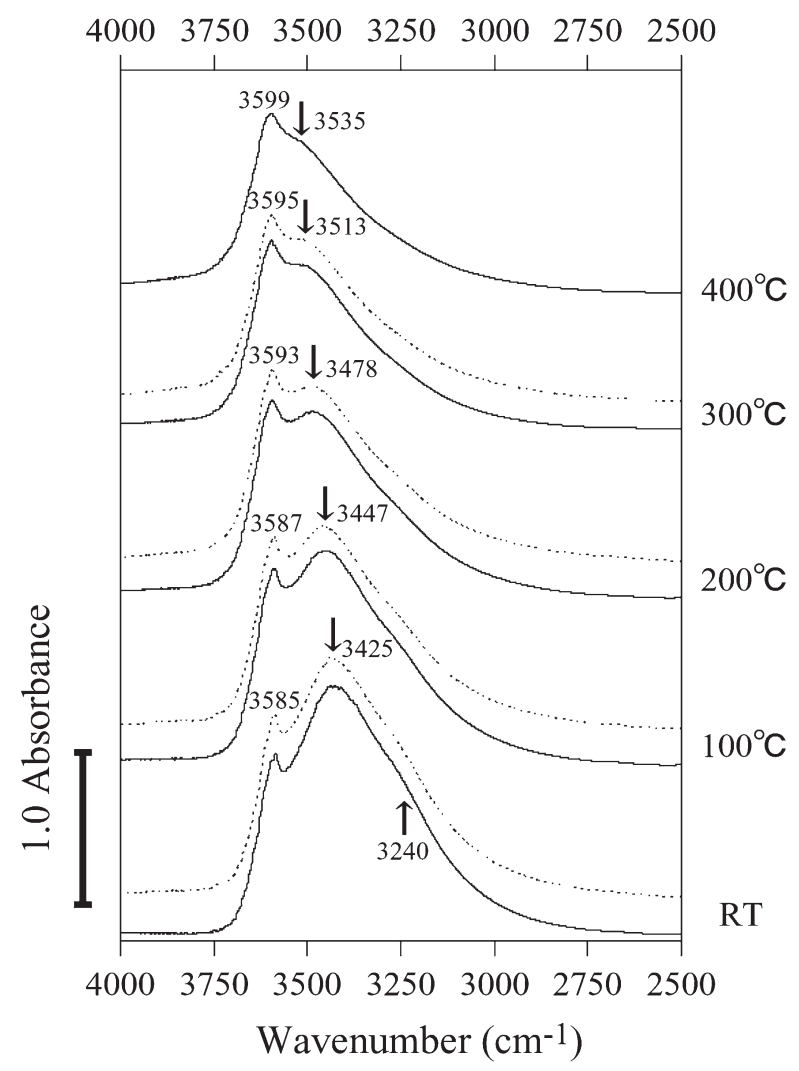

Figure 1. In-situ high temperature IR spectra of the chalcedony thin section $\left(170 \mu \mathrm{m}\right.$ thick) from RT to $400{ }^{\circ} \mathrm{C}$. Two bands at $3585 \mathrm{~cm}^{-1}$ and $3425 \mathrm{~cm}^{-1}$ (RT) are due to hydroxyl ( $\left.\mathrm{Si}-\mathrm{OH}\right)$ and $\mathrm{H}_{2} \mathrm{O}$, respectively. The solid spectra upon heating from RT to 400 ${ }^{\circ} \mathrm{C}$ can be recovered upon cooling (dotted spectra from $400{ }^{\circ} \mathrm{C}$ to RT) indicating the reversibility of the bands without dehydration.

moganite peaks were observed in addition to dominant quartz peaks.

The IR instrument (FT-IR 620+IRT-30) used for experiments was equipped with a ceramic IR source, a $\mathrm{KBr}$ beam splitter and a MCT detector. A heating stage (Linkam TS-1500) was set on the sample stage of the IR microscope. The step heating experiments were carried out using the sample thin section. IR transmission spectra of the sample were first measured at RT and from $100{ }^{\circ} \mathrm{C}$ to $400{ }^{\circ} \mathrm{C}$ at $50{ }^{\circ} \mathrm{C}$ intervals. The isothermal dehydration experiments were conducted at $550{ }^{\circ} \mathrm{C}$ and dehydration behavior was monitored in-situ until 500 minutes. Another series of IR measurement was conducted at RT after quenching from heating for 0 to 500 minutes at $550^{\circ} \mathrm{C}$.

\section{RESULTS}

\section{Step heating experiments}

The in-situ IR spectra from RT to $400{ }^{\circ} \mathrm{C}$ are shown in Figure 1. At RT, a sharp band at $3585 \mathrm{~cm}^{-1}$ and a broad

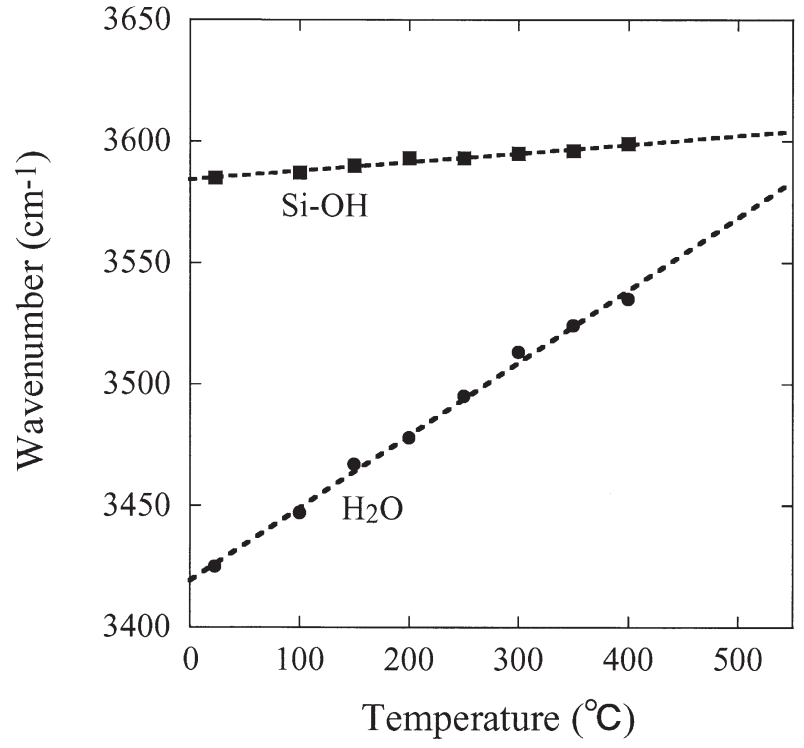

Figure 2. The band shifts of $\mathrm{Si}-\mathrm{OH}$ and $\mathrm{H}_{2} \mathrm{O}$ for high temperatures based on the data in Figure 1. The linear shifts of $\mathrm{Si}-\mathrm{OH}$ and $\mathrm{H}_{2} \mathrm{O}$ bands are observed $\left(1.8 \mathrm{~cm}^{-1} / 50{ }^{\circ} \mathrm{C}\right.$ and $15 \mathrm{~cm}^{-1} / 50{ }^{\circ} \mathrm{C}$, respectively).

band around $3425 \mathrm{~cm}^{-1}$ with a shoulder at $3240 \mathrm{~cm}^{-1}$ are observed. The $3585 \mathrm{~cm}^{-1}$ band is considered to be due to stretching mode of hydroxyl of $\mathrm{Si}-\mathrm{OH}$ (e.g., Graetsch et al., 1985). The broad band around $3425 \mathrm{~cm}^{-1}$ with a shoulder at $3240 \mathrm{~cm}^{-1}$ is similar to that of liquid water $\left(\mathrm{H}_{2} \mathrm{O}\right)$ (Aines and Rossman, 1984). For increasing temperature, the $\mathrm{H}_{2} \mathrm{O}$ band at $3425 \mathrm{~cm}^{-1}$ significantly shifts to higher frequencies, while the hydroxyl band at $3585 \mathrm{~cm}^{-1}$ shifts slightly. These changes of absorption bands with temperature are reversible between RT and $400{ }^{\circ} \mathrm{C}$ upon heating (solid spectra) and cooling (dotted spectra) (Fig. 1). The hydroxyl and $\mathrm{H}_{2} \mathrm{O}$ bands are found to shift linearly with temperature to higher frequencies at a rate of $1.8 \mathrm{~cm}^{-1} / 50$ ${ }^{\circ} \mathrm{C}$ and $15 \mathrm{~cm}^{-1} / 50{ }^{\circ} \mathrm{C}$, respectively (Fig. 2). Because of the reversibility of the absorption bands (Fig. 1), these changes are not from dehydration but from changes with temperature in physicochemical states of hydroxyl and $\mathrm{H}_{2} \mathrm{O}$ in the microcrystalline quartz.

\section{Isothermal dehydration experiments}

In order to study dehydration behavior of the chalcedony at a higher temperature than $400{ }^{\circ} \mathrm{C}$, isothermal changes in IR spectra were measured in-situ at $550{ }^{\circ} \mathrm{C}$ (Fig. 3). The total band areas gradually decrease with time, indicating in-situ dehydration of water. However, since the $\mathrm{Si}-\mathrm{OH}$ and $\mathrm{H}_{2} \mathrm{O}$ bands are supposed to be closely overlapping $\left(3604 \mathrm{~cm}^{-1}\right.$ vs. $3583 \mathrm{~cm}^{-1}$ from extrapolation of the linear trends in Fig. 2), the origin of the total water band decrease is not clear. 


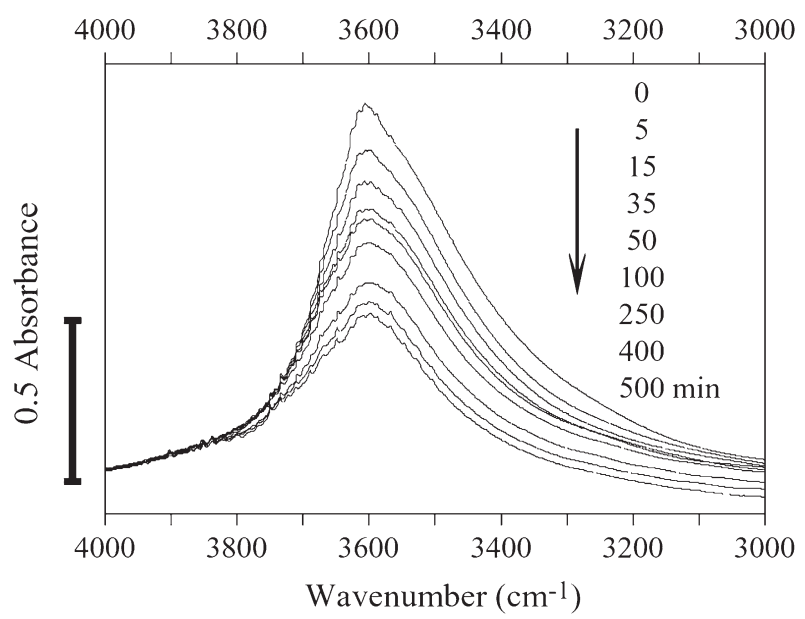

Figure 3. Isothermal in-situ IR spectra at $550{ }^{\circ} \mathrm{C}$ for the chalcedony thin section $(260 \mu \mathrm{m}$ thick). The total band area decreased from 0 to 500 minutes showing dehydration.

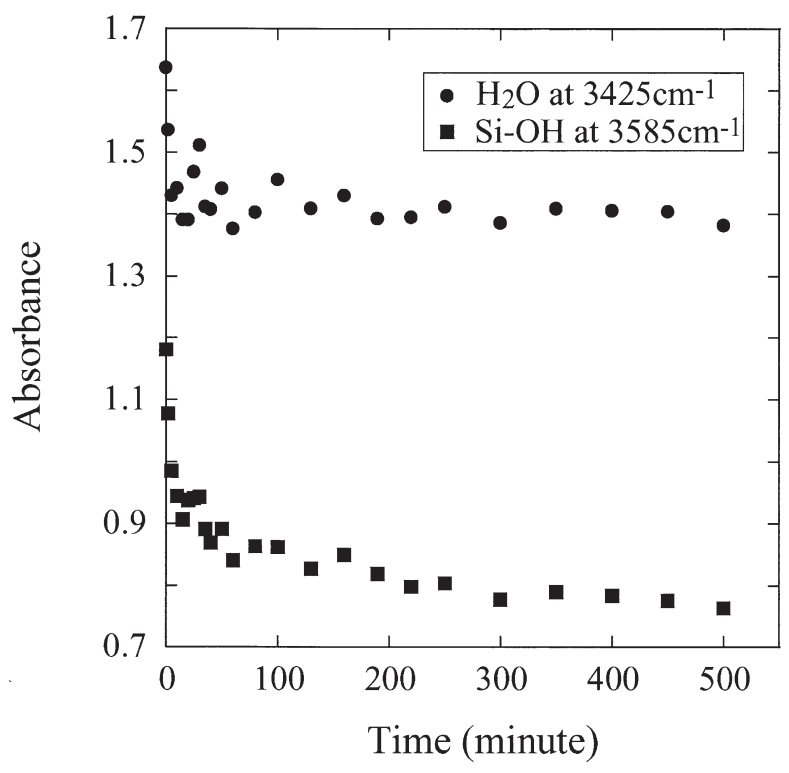

Figure 5. The decreases with time of absorbance at $3425 \mathrm{~cm}^{-1}$ due to $\mathrm{H}_{2} \mathrm{O}$ and $3585 \mathrm{~cm}^{-1}$ absorbance due to $\mathrm{Si}-\mathrm{OH}$ during the isothermal heating at $550{ }^{\circ} \mathrm{C}$ in Figure 4. The remarkable decrease of $\mathrm{Si}-\mathrm{OH}$ is observed within 50 minutes $(30 \%)$, while the $\mathrm{H}_{2} \mathrm{O}$ band decreases slightly (12\%).

Because the two bands are well separated at RT (3585 $\mathrm{cm}^{-1}$ vs. $3425 \mathrm{~cm}^{-1}$; Figs. 1 and 2), IR spectra were measured at RT after quenching from $550{ }^{\circ} \mathrm{C}$ heating from 0 to 500 minutes. The $3585 \mathrm{~cm}^{-1}$ band due to $\mathrm{Si}-\mathrm{OH}$ shows a remarkable decrease with time (Fig. 4). On the other hand, $\mathrm{H}_{2} \mathrm{O}$ band around $3425 \mathrm{~cm}^{-1}$ does not show significant changes. The peak heights at $3585 \mathrm{~cm}^{-1}$ and 3425 $\mathrm{cm}^{-1}$ after baseline correction were plotted against time in Figure 5. The $3585 \mathrm{~cm}^{-1}$ peak height rapidly decreases from about 1.2 (absorbance unit) to about 0.85 (30\% decrease) within first 50 minutes and the decrease becomes

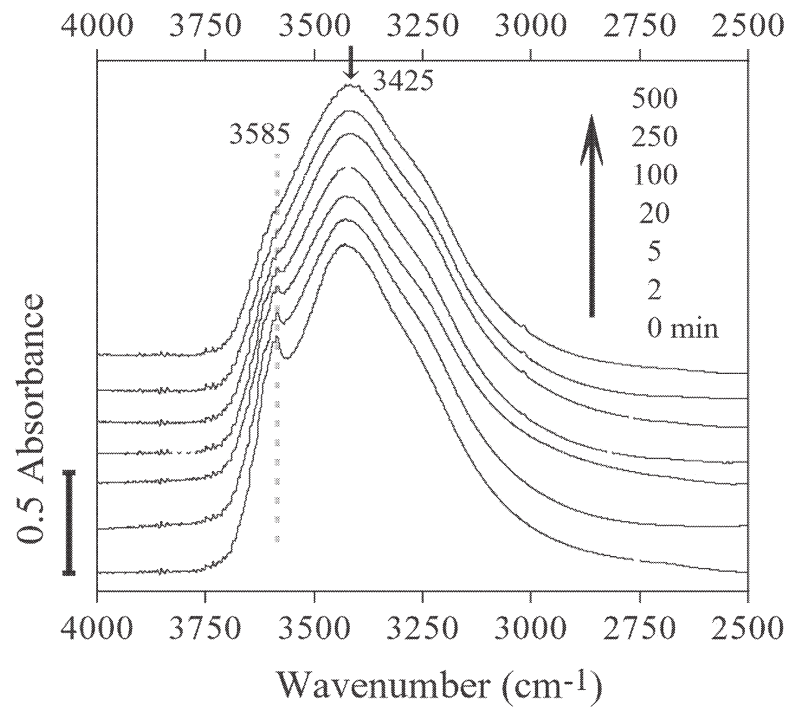

Figure 4. IR spectra at RT quenched after heating at $550{ }^{\circ} \mathrm{C}$ from 0 to 500 minutes for the chalcedony thin section $(170 \mu \mathrm{m}$ thick).

gentle. The $3425 \mathrm{~cm}^{-1}$ peak height appears to decrease slightly from about 1.65 to about 1.45 (12\% decrease) within first 50 minutes and it remains almost unchanged around 1.4. Therefore, the band decreases in Figure 3 (about 50\% decrease for 500 minutes) may reflect the major decrease of $\mathrm{Si}-\mathrm{OH}$ together with a minor contribution of $\mathrm{H}_{2} \mathrm{O}$ decrease.

\section{DISCUSSION}

\section{Physicochemical states of water in the chalcedony at high temperatures}

The slight shift of band position of hydroxyl in the chalcedony shown in Figures 1 and 2 can be originated from the slight increase of hydrogen bond distances (Libowitzky, 1999) in quartz, through the thermal expansion of the quartz lattice (e.g., Kihara, 2001).

On the other hand, the $\mathrm{H}_{2} \mathrm{O}$ band in the microcrystalline quartz shifted significantly to higher frequencies at higher temperatures $\left(15 \mathrm{~cm}^{-1} / 50{ }^{\circ} \mathrm{C}\right)$. It is generally accepted that at RT liquid water consists of various degrees of coordination number of hydrogen bonding (maximum number is four; two donors and two acceptors in a single $\mathrm{H}_{2} \mathrm{O}$ molecule). The dominant coordinating number of hydrogen bonding at RT is two and three, while zero, one and four coordinating numbers are fewer (e.g., Brubach et al., 2005). The frequency of $\mathrm{H}_{2} \mathrm{O}$ stretching shifts to higher region for decreasing coordinating number of hydrogen bond (Brubach et al., 2005). Therefore, the broad IR band of $\mathrm{H}_{2} \mathrm{O}$ in the chalcedony around $3425 \mathrm{~cm}^{-1}$ at RT is dominantly due to the two and three coordinating numbers of hydrogen bonding. The increase of higher frequency 
components for higher temperatures can be interpreted as the decrease of coordinating numbers of hydrogen bonding becoming less than two above the supercritical temperatures (Nakahara et al., 2001). These results indicate that $\mathrm{H}_{2} \mathrm{O}$ in the microcrystalline quartz behaves similarly to liquid water at high temperatures despite its presence in confined pores and grain boundaries.

\section{Dehydration behavior in the chalcedony}

The isothermal heating experiments of the chalcedony suggested the dominant dehydration of $\mathrm{Si}-\mathrm{OH}$ species, while $\mathrm{H}_{2} \mathrm{O}$ showed only a slight decrease (Figs. 4 and 5). On the other hand, the remarkable decrease of $\mathrm{H}_{2} \mathrm{O}$ band around $3425 \mathrm{~cm}^{-1}$ compared with the $\mathrm{Si}-\mathrm{OH}$ band around $3585 \mathrm{~cm}^{-1}$ and the appearance of the additional band at $3740 \mathrm{~cm}^{-1}$ due to isolated surface $\mathrm{Si}-\mathrm{OH}$ were reported during the heating of chalcedonic quartz (Graetsch et al., 1985; Yamagishi et al., 1997). Despite the liquidlike states of water in pores and grain boundaries of the microcrystalline quartz, the present results indicate possible stability against dehydration at high temperatures of at least a part of liquid-like water in the microcrystalline quartz. Therefore, further systematic studies are needed to elucidate the dehydration behavior in the microcrystalline quartz in relation to the physicochemical environments of water in different textures such as grain size, pore size, grain boundary thickness etc.

\section{ACKNOWLEDGMENTS}

The authors thank K. Tokiwai and T. Yokoyama for their technical supports and valuable discussion.

\section{REFERENCES}

Aines, R.D. and Rossman, G.R. (1984) Water in minerals? A peak in the infrared. Journal of Geophysical Research, 89, 4059-4071.

Brubach, J.B., Mermet, A., Filabozzi, A., Gerschel, A. and Roy, P. (2005) Signatures of the hydrogen bonding in the infrared bands of water. Journal of Chemical Physics, 122, Art. No. 184509.

Farver, J.R. and Yund, R.A. (1992) Oxygen diffusion in a finegrained quartz aggregate with wetted and nonwetted microstructures. Journal of Geophysical Reserch, 97, 14017-14029.

Flörke, O.W., Graetsch, H., Martin, B., Röller, K. and Wirth, R. (1991) Nomenclature of micro- and non-crystalline silica minerals, based on structure and microstructure. Neues Jahrbuch für Mineralogie Abhandlungen, 163, 19-42.

Frondel, C. (1982) Structural hydroxyl in chalcedony (Type B quartz). American Mineralogist, 67, 1248-1257.

Graetsch, H. (1994) Structural characteristics of opaline and microcrystalline silica minerals. In Silica: Physical behavior, geochemistry, and materials applications, Reviews in Mineralogy, 29 (Heaney, P.J., Prewitt, C.T. and Gibbs, G.V. Eds.). Mineralogical Society of America, Washington, D.C., 209-232.

Graetsch, H., Flörke, O.W. and Miehe, G. (1985) The nature of water in chalcedony and opal-C from Brazilian agate geodes. Physics and Chemistry of Minerals, 12, 300-306.

Hiraga, T., Nishikawa, O., Nagase, T. and Akizuki, M. (2001) Morphology of intergranular pores and wetting angles in pelitic schists studied by transmission electron microscopy. Contributions to Mineralogy and Petrology, 141, 613-622.

Ito, Y. and Nakashima, S. (2002) Water distribution in low-grade siliceous metamorphic rocks by micro-FTIR and its relation to grain size: a case from the Kanto Mountain region, Japan. Chemical Geology, 189, 1-18.

Kihara, K. (2001) Molecular dynamics interpretation of structural changes in quartz. Physics and Chemistry of Minerals, 28, 365-376.

Libowitzky, E. (1999) Correlation of O-H stretching frequencies and $\mathrm{O}-\mathrm{H} \cdots \mathrm{O}$ hydrogen bond lengths in minerals. Monatshefte für Chemie, 130, 1047-1059.

Nakahara, M., Matubayasi, N., Wakai, C. and Tsujino, Y. (2001) Structure and dynamics of water: from ambient to supercritical. Journal of Molecular Liquids, 90, 75-83.

Yamagishi, H., Nakashima, S. and Ito, Y. (1997) High temperature infrared spectra of hydrous microcrystalline quartz. Physics and Chemistry of Minerals, 24, 66-74.

Suzuki, S. and Nakashima, S. (1999) In-situ IR measurements of $\mathrm{OH}$ species in quartz at high temperatures. Physics and Chemistry of Minerals, 26, 217-225.

Manuscript received October 22, 2007

Manuscript accepted December 11, 2007

Published online March 22, 2008

Manuscript handled by Koichiro Fujimoto 